\title{
Total smoking bans in psychiatric inpatient services: a survey of perceived benefits, barriers and support among staff
}

\author{
Paula Wye*1,2, Jenny Bowman1, John Wiggers2,3, Amanda Baker ${ }^{4}$, Jenny Knight2,3, Vaughan Carr5,6, Margarett Terry ${ }^{7}$ \\ and Richard Clancy $^{7}$
}

\begin{abstract}
Background: The introduction of total smoking bans represents an important step in addressing the smoking and physical health of people with mental illness. Despite evidence indicating the importance of staff support in the successful implementation of smoking bans, limited research has examined levels of staff support prior to the implementation of a ban in psychiatric settings, or factors that are associated with such support. This study aimed to examine the views of psychiatric inpatient hospital staff regarding the perceived benefits of and barriers to implementation of a successful total smoking ban in mental health services. Secondly, to examine the level of support among clinical and non-clinical staff for a total smoking ban. Thirdly, to examine the association between the benefits and barriers perceived by clinicians and their support for a total smoking ban in their unit.
\end{abstract}

Methods: Cross-sectional survey of both clinical and non-clinical staff in a large inpatient psychiatric hospital immediately prior to the implementation of a total smoking ban.

Results: Of the 300 staff, 183 (61\%) responded. Seventy-three (41\%) of total respondents were clinical staff, and 110 (92\%) were non-clinical staff. More than two-thirds of staff agreed that a smoking ban would improve their work environment and conditions, help staff to stop smoking and improve patients' physical health. The most prevalent clinician perceived barriers to a successful total smoking ban related to fear of patient aggression (89\%) and patient non-compliance (72\%). Two thirds (67\%) of all staff indicated support for a total smoking ban in mental health facilities generally, and a majority (54\%) of clinical staff expressed support for a ban within their unit. Clinical staff who believed a smoking ban would help patients to stop smoking were more likely to support a smoking ban in their unit.

Conclusions: There is a clear need to more effectively communicate to staff the evidence that consistently applied smoking bans do not increase patient aggression. There is also a need to communicate the benefits of smoking bans in aiding the delivery of smoking cessation care, and the benefits of both smoking bans and such care in aiding patients to stop smoking.

\section{Background}

Smoking remains responsible for the greatest disease burden in Australia [1] and elsewhere [2]. For those with psychiatric disorders, the prevalence of smoking $[3,4]$ is much higher than among the general population [5]. In mental health inpatient settings in Australia [6,7] and elsewhere [8], high smoking rates have been reported.

\footnotetext{
* Correspondence: Paula.Wye@newcastle.edu.au

1 School of Psychology, University of Newcastle, University Drive, Newcastle, 2308 Australia

Full list of author information is available at the end of the article
}

Consequently, those with a mental illness are more likely to develop and die from smoking-related diseases than are those without such an illness [9].

The introduction of total smoking bans represents an important step in addressing the harm caused by tobacco smoking for people with a mental illness [10]. The World Health Organisation [11] recommends that all health care premises and immediate surroundings should be smokefree. Smoke-free workplaces in general not only protect noni $i^{1 / 2}$ smokers from the dangers of passive smoking [12], they also encourage smokers to quit or to reduce con- 
sumption [12-14]. Smoking bans are now the norm for indoor workers [15]. Total bans, where smoking is banned completely, are more effective than partial bans, where smoking is still allowed in designated areas [14].

Although general hospital settings have successfully moved to smoke-free environments [16], health services internationally are struggling with the challenges involved in implementing total smoking bans in mental health settings $[17,18]$. Evidence suggests that total smoking bans are more sustainable than partial smoking bans $[10,19]$, more effective at reducing staff exposure to environmental tobacco smoke [19], and less likely to result in patient complaints or verbal aggression [10]. Additionally, the provision of nicotine dependence treatment is more likely to occur in psychiatric inpatient settings that adhere to total smoking bans [20,21]. Partial bans continue to condone smoking, sending a message that smoking is still an acceptable practice. In addition, partial bans do little to encourage patients to consider quitting, nor do they influence staff behaviour to provide nicotine dependence treatment $[21,22]$. This issue of changing staff and patient behaviour is a particularly important argument for total smoking bans [22-24].

The determinants of successful implementation of total smoking bans in mental health services have been suggested to include structural and systemic changes to health services, effective leadership, and staff acceptance $[10,22,24]$. While there is evidence that the implementation of a total smoking ban is accepted by the majority of mental health patients $[10,19]$ and may increase patient optimism about success in quitting [10,25], a number of studies report negative staff views as barriers to the successful implementation of such bans $[19,20,26]$. Commonly reported staff-expressed barriers relate to fears of patient aggression [27], ethical concerns $[19,20,28]$ and staff and patient compliance issues $[19,20,26]$.

The ability to generalize from the findings of previous research regarding staff views towards smoking bans is limited by a number of methodological features and differences in methodologies between studies. Firstly, very few studies have examined staff support for smoking bans in mental health care settings that applied to both buildings and grounds; that is, a total smoking ban. Only four such studies were identified in the published literature over the last decade $[14,20,29,30]$. These four studies, undertaken in the Netherlands [20], the U.K. [29,30], and Switzerland [14], reported that $19 \%, 32 \%, 60 \%$ and $37 \%$ of psychiatric staff respectively were supportive of a total smoking ban. In contrast, studies of partial bans in mental health settings have reported much higher support $[14,31]$.

Secondly, the four reported studies were conducted in different mental health settings. The Willemsen et al study involved aggregated data from psychiatric inpa- tient, outpatient, and sheltered home settings with a range of smoking restrictions in place [20], and the remaining studies were conducted in a variety of psychiatric unit settings $[14,29,30]$. The variety in reported levels of support for total smoking bans suggests differences in staff support for total smoking bans between different clinical settings.

Thirdly, despite the requirement for smoking bans to be complied with by all staff for the protection of all staff and patients, research regarding the acceptability of such bans has focused on the views of clinical staff only [14,20,22,24,26-31]. Given the different roles of clinical and non-clinical staff, and differences in the extent of contact with patients between such staff, the implementation of a smoking ban is likely to have different impacts on these staff groups, and hence likely to result in differences in perceived benefits, barriers and support. For the purposes of this study, 'clinical staff' is defined as those staff who in the course of their normal role, provided patient care.

Fourthly, the reported studies of total smoking bans were conducted at different times relative to the implementation of a total smoking ban. Two of the studies $[14,29]$ indicated that measures of support for a total smoking ban were conducted following the implementation of such a ban. In contrast, the two studies[20,30] that reported the highest $(60 \%)$ and lowest level of support for a total smoking ban (19\%) respectively, were conducted prior to, and not in the context of an impending total smoking ban. Comparison of the reported levels of support between such studies is therefore of limited value, particularly as a person's response to change is influenced by the perceived personal consequence of the change, which in turn is influenced by the proximity or immediacy of the proposed change to the individual [32].

Further, two of the studies [14,29] reported significant levels of non-compliance following the implementation of a ban, as evidenced by respondent exposure to second hand smoke (35\%) [14], and continued staff smoking (59\%) [29]. The extent to which a smoking ban has been successfully implemented might be expected to impact on the extent and nature of perceived benefits, barriers and support for a smoking ban.

Despite the importance of identifying barriers and facilitators of staff support as a basis for designing the implementation of smoking bans, few studies have examined factors that are predictive of staff support for smoking bans. With respect to research specific to total smoking bans in psychiatric settings, only one study has done so, indicating that the support of Dutch clinical staff for a total smoking ban was positively associated with the belief that such a policy results in less annoyance from second hand tobacco smoke [20]. Similarly, a study to determine predictors of support for smoking bans among 
public officials found that support is significantly more prevalent among those who believe: that tobacco use is a serious problem in their community; breathing environmental tobacco smoke is a serious problem for nonsmokers; government should get involved with people's decisions about smoking; in providing smoking-cessation programs for public employees; and have smoked less than 100 cigarettes during their lifetime [33]. No research has as yet been reported in Australia indicating staff support for either total or partial smoking bans in mental health settings.

This study was undertaken to determine clinical and non-clinical staff views regarding the imminent implementation of a total smoking ban in a large psychiatric hospital in Australia. The study had three aims: 1. to ascertain staff perceived benefits of, and barriers to a successful total smoking ban, 2. to investigate the level of staff support for total smoking bans within mental health services and their own units; and 3. to examine the association between clinician perceived benefits and barriers to a successful total smoking ban, and their support for such a ban in their unit.

\section{Methods}

\section{Design \& Setting}

A cross-sectional survey of both clinical and non-clinical staff at a large psychiatric inpatient hospital in the state of New South Wales, Australia was undertaken. The facility had approximately 2000 patient discharges per annum, consisting of 80 beds in six units: a psychiatric emergency centre, an intensive care unit, two general acute units, a dual diagnoses (concurrent mental health and substance use) unit, and an aged care unit.

A 'smoke free workplace policy' that included a total smoking ban in both buildings and grounds was to be implemented in the facility two weeks immediately following the survey period. The introduction of the policy was in accordance with directions from the New South Wales Department of Health that all health facilities in the state were to become smoke-free. Preparations for the local implementation of the policy included: establishment of service-wide and mental health specific policy implementation committees; allocation of resources to the implementation of the policy; communication to staff and the community regarding the introduction of the policy; creation of a mental health implementation project officer position for twelve months; provision of quit and abstinence assistance for staff who smoked; placement of no smoking signage, removal of ashtrays, clinical staff consultations, and the provision of staff training.

\section{Participants}

A total of 300 staff were employed at the site, of which $60 \%$ (approximately 180 staff) occupied clinical positions, that is, performed a role that involved patient care. The remainder occupied non-clinical positions (for example, administrative and support staff).

\section{Procedure}

This research was approved by the Hunter New England Human Research Ethics Committee and the University of Newcastle Human Research Ethics Committee. Two questionnaires, one for clinical staff, and one for nonclinical staff were developed utilising concepts used in previous similar studies $[22,30,34]$. In addition, data from focus groups held with staff and ex-patients regarding a total smoking ban and nicotine dependence treatment guided the development of the questionnaires. Domains included identified issues to clinical practice change, and organisational policy objectives. Piloting of the survey with mental health clinical staff from other settings provided additional questions in the final version. The two questionnaires were very similar in content, with the clinical staff questionnaire including additional items relating to clinical care issues. All staff were invited by management email and staff newsletter to complete a pen and paper questionnaire during the two week survey period. Although completion of the questionnaire was voluntary, staff were encouraged to complete the questionnaire by management, and several prompts through emails and newsletters were provided. Questionnaires and return boxes were left in key locations (for example staff stations, tea rooms, reception areas) and research staff regularly checked each location during the survey period.

\section{Measures}

\section{Staff Demographic Characteristics}

Demographic questions addressed respondent gender, age, highest level of education, job description, length of time in current position, current smoking status, and exposure to second hand tobacco smoke at work (yes, no) (Table 1). Clinical staff were also asked to indicate whether they had received training in smoking cessation care and whether they were interested in doing so.

\section{Perceived benefits of a total smoking ban}

Both surveys contained a question which asked respondents to indicate their level of agreement with 14 statements regarding potential benefits of a total smoking ban ('strongly disagree, disagree, uncertain, agree, strongly agree') (Table 2).

\section{Clinician perceived barriers to implementation of a total smoking ban}

The survey for clinical staff included an item asking respondents to indicate their level of agreement with 19 statements regarding possible clinical barriers to a total smoking ban ('strongly disagree, disagree, uncertain, agree, strongly agree') (Table 3 ). 


\begin{tabular}{|c|c|c|c|c|c|c|}
\hline & \multicolumn{2}{|c|}{ Clinical Staff (73) } & \multicolumn{2}{|c|}{ Non-Clinical Staff (110) } & \multicolumn{2}{|c|}{ Total (183) } \\
\hline & $\%$ & $\mathbf{n}$ & $\%$ & $\mathbf{n}$ & $\%$ & $\mathbf{N}$ \\
\hline Female & 60 & 44 & 71 & 77 & 66 & 121 \\
\hline \multicolumn{7}{|l|}{ Age } \\
\hline$\leq 35$ & 45 & 33 & 43 & 47 & 44 & 80 \\
\hline $36-45$ & 23 & 17 & 20 & 22 & 21 & 39 \\
\hline $46+$ & 32 & 23 & 37 & 40 & 35 & 63 \\
\hline \multicolumn{7}{|l|}{ Education } \\
\hline$<\mathrm{HSC}$ & 4 & 3 & 22 & 24 & 15 & 27 \\
\hline $\mathrm{HSC}$ & 10 & 7 & 28 & 30 & 21 & 37 \\
\hline Undergraduate Degree & 39 & 28 & 29 & 31 & 33 & 59 \\
\hline Postgraduate Degree & 47 & 33 & 21 & 23 & 31 & 56 \\
\hline \multicolumn{7}{|l|}{ Length of Time in Job } \\
\hline$\leq 4$ years & 47 & 34 & 60 & 65 & 54 & 99 \\
\hline $4+$ years & 53 & 39 & 40 & 44 & 46 & 83 \\
\hline \multicolumn{7}{|l|}{ Smoking Status } \\
\hline Current smoker & 19 & 14 & 23 & 25 & 21 & 39 \\
\hline Former smoker & 33 & 24 & 24 & 22 & 26 & 48 \\
\hline Never smoker & 48 & 35 & 55 & 60 & 52 & 95 \\
\hline Exposed to ETS at work & 78 & 57 & 31 & 34 & 50 & 91 \\
\hline Trained in smoking care (yes) & 19 & 13 & na & na & na & na \\
\hline Interested in such training (yes) & 72 & 51 & na & na & na & na \\
\hline
\end{tabular}

\section{Support for a total smoking ban}

Both questionnaires included a question asking whether the respondent supported a total smoking ban throughout all mental health services ('strongly unsupportive, unsupportive, no view either way, supportive, strongly supportive') (Table 4). The clinical staff survey also asked respondents to indicate their level of agreement with a total smoking ban in their unit ('strongly disagree, disagree, unsure, agree, strongly agree').

\section{Analysis}

All analyses were undertaken using SPSS Version 15 [35]. Descriptive statistics were used to report respondent demographics, perceived benefits of, and barriers to a total smoking ban, and support for a total smoking ban.

Response categories for staff perceived benefits and barriers were reduced to three: 'agree, uncertain, disagree'. Response categories for clinician and non-clinician support for a ban in mental health services generally were reduced to two: 'strongly unsupportive/unsupportive/no view either way'; and 'supportive/strongly supportive'. Response categories relating to clinician support for a ban in their unit were reduced to two: 'strongly disagree/disagree/unsure'; and 'agree/strongly agree'.
Possible differences between clinical and non-clinical staff in their perceptions of the benefits of a total smoking ban, and in their support for such a ban in mental health services generally were assessed by chi square analyses.

Chi square analysis was initially undertaken to determine the univariate associations between staff demographic characteristics and clinical staff perceptions of the benefits and barriers of a total smoking ban, and their support for such a ban. Multiple statistical testing was accounted for by setting the significance level to $\mathrm{p}<0.01$ $[36,37]$. Perceived benefits and barriers that had the strongest relationship with support for a total smoking ban were entered into a backward stepwise logistic regression model. The number of variables initially entered into the model was limited by the size of the sample. The final model contained all variables with $\mathrm{p}<0.05$.

\section{Results}

\section{Participants}

Of the 180 clinical and 120 non-clinical staff available to complete the survey, 183 (61\%) did so: 73 clinical staff (41\%), and 110 non-clinical staff (92\%) (Table 1). Of the clinical respondents, $56 \%$ identified as nurses, $26 \%$ as allied health and $18 \%$ as medical/psychiatry Of the non- 


\begin{tabular}{|c|c|c|c|c|c|c|c|c|c|c|c|c|c|c|c|c|c|c|}
\hline & \multicolumn{6}{|c|}{ Agree } & \multicolumn{6}{|c|}{ Uncertain } & \multicolumn{6}{|c|}{ Disagree } \\
\hline & \multicolumn{2}{|c|}{ Clinical } & \multicolumn{2}{|c|}{ Non Clinical } & \multicolumn{2}{|c|}{ Total } & \multicolumn{2}{|c|}{ Clinical } & \multicolumn{2}{|c|}{ Non Clinical } & \multicolumn{2}{|c|}{ Total } & \multicolumn{2}{|c|}{ Clinical } & \multicolumn{2}{|c|}{ Non Clinical } & \multicolumn{2}{|c|}{ Total } \\
\hline & $\%$ & $\mathrm{n}$ & $\%$ & $\mathrm{n}$ & $\%$ & $\mathbf{n}$ & $\%$ & $\mathrm{n}$ & $\%$ & $\mathrm{n}$ & $\%$ & $\mathbf{n}$ & $\%$ & $\mathrm{n}$ & $\%$ & $\mathrm{n}$ & $\%$ & $\mathbf{n}$ \\
\hline Make the place look/smell better (183) & 88 & 64 & 76 & 83 & 81 & 147 & 8 & 6 & 14 & 15 & 11 & 21 & 4 & 3 & 10 & 11 & 8 & 14 \\
\hline Help staff stop smoking (183) & 67 & 49 & 65 & 71 & 66 & 120 & 18 & 13 & 27 & 29 & 23 & 42 & 15 & 11 & 8 & 9 & 11 & 20 \\
\hline Improve patient physical health (183) & 69 & 50 & 62 & 68 & 65 & 118 & 17 & 12 & 27 & 29 & 23 & 41 & 14 & 10 & 11 & 12 & 12 & 22 \\
\hline Improve working conditions (183) & 62 & 45 & 66 & 72 & 64 & 117 & 25 & 18 & 17 & 19 & 20 & 37 & 14 & 10 & 16 & 18 & 15 & 28 \\
\hline Increase patient quality of life (183) & 41 & 30 & 39 & 43 & 40 & 73 & 33 & 24 & 42 & 46 & 38 & 70 & 26 & 19 & 18 & 20 & 21 & 39 \\
\hline Help patients stop smoking (183) & 41 & 30 & 36 & 39 & 38 & 69 & 15 & 21 & 34 & 37 & 29 & 52 & 38 & 28 & 30 & 33 & 33 & 61 \\
\hline Increase the quality of care (183) & 29 & 21 & 32 & 35 & 31 & 56 & 45 & 33 & 50 & 54 & 48 & 87 & 26 & 19 & 18 & 20 & 21 & 39 \\
\hline Improve patient mental health (183) & 36 & 26 & 24 & 26 & 29 & 52 & 27 & 20 & 44 & 48 & 37 & 68 & 37 & 27 & 32 & 35 & 34 & 62 \\
\hline Make the unit safer (183) & 26 & 19 & 27 & 29 & 26 & 48 & 31 & 23 & 39 & 43 & 36 & 66 & 42 & 31 & 34 & 37 & 37 & 68 \\
\hline Reduce medication use (72) & 17 & 12 & & & & & 28 & 20 & & & & & 56 & 40 & & & & \\
\hline Create less work (183) & 18 & 13 & 8 & 9 & 12 & 22 & 33 & 24 & 39 & 43 & 37 & 67 & 49 & 36 & 52 & 57 & 51 & 93 \\
\hline Increase rapport between patients (72) & 11 & 8 & & & & & 37 & 27 & & & & & 51 & 37 & & & & \\
\hline Decrease client aggression (183) & 10 & 7 & 7 & 8 & 8 & 15 & 33 & 24 & 30 & 33 & 31 & 57 & 57 & 42 & 62 & 68 & 60 & 110 \\
\hline Make patients happier (183) & 3 & 2 & 7 & 8 & 5 & 10 & 37 & 27 & 35 & 38 & 35 & 65 & 60 & 44 & 58 & 63 & 59 & 107 \\
\hline
\end{tabular}


Table 3: Clinician perceived barriers to a successful total smoking ban

\begin{tabular}{|c|c|c|c|c|c|c|}
\hline & \multicolumn{2}{|c|}{ Agree } & \multicolumn{2}{|c|}{ Uncertain } & \multicolumn{2}{|c|}{ Disagree } \\
\hline & $\%$ & $\mathrm{n}$ & $\%$ & $\mathrm{n}$ & $\%$ & $\mathrm{n}$ \\
\hline Fear of patient aggression & 89 & 63 & 4 & 3 & 7 & 5 \\
\hline Patients will continue to smoke & 72 & 52 & 14 & 10 & 14 & 10 \\
\hline Staff are too busy with patient mental health & 61 & 43 & 15 & 11 & 24 & 17 \\
\hline Lack of staff cohesion/consistency & 59 & 42 & 24 & 17 & 17 & 12 \\
\hline Staff resistance to change & 58 & 41 & 22 & 16 & 20 & 14 \\
\hline Lack of staff time & 57 & 41 & 21 & 15 & 22 & 16 \\
\hline Lack of staff confidence & 53 & 38 & 21 & 15 & 26 & 19 \\
\hline Lack of staff knowledge & 52 & 37 & 16 & 11 & 32 & 23 \\
\hline Staff will continue to smoke & 51 & 37 & 24 & 17 & 25 & 18 \\
\hline Lack information about policy/procedures & 49 & 35 & 21 & 15 & 30 & 21 \\
\hline Processes aren't developed & 44 & 31 & 37 & 26 & 19 & 14 \\
\hline Support systems aren't in place & 44 & 32 & 36 & 26 & 19 & 14 \\
\hline Lack of staff skills & 43 & 30 & 14 & 10 & 43 & 30 \\
\hline Insufficient training provided & 40 & 29 & 29 & 21 & 31 & 22 \\
\hline Lack of staff interest & 36 & 26 & 26 & 19 & 38 & 27 \\
\hline Lack of resources & 35 & 25 & 42 & 30 & 23 & 16 \\
\hline Lack of sustainability & 32 & 23 & 32 & 23 & 36 & 26 \\
\hline Lack of management support & 29 & 21 & 25 & 18 & 46 & 33 \\
\hline Lack of staff commitment & 26 & 19 & 38 & 27 & 36 & 26 \\
\hline
\end{tabular}

clinical respondents, $38 \%$ identified as administrative with patient contact, $30 \%$ as administrative with no patient contact, $14 \%$ as researchers, and $11 \%$ as hospitality staff (Table 1). Clinical staff were more likely to have a tertiary education $\left(\chi^{2}=26.033, \mathrm{p}=.000\right)$ and to report being exposed to other people's smoke at work $\left(\chi^{2}=\right.$ 38.449, $\mathrm{p}=.000)$

\section{Perceived benefits of a total smoking ban}

The majority of respondents agreed that a total smoking ban would make their work environment look/smell better $(81 \%)$ and improve working conditions (65\%) (Table 2 ). Fewer agreed that a total smoking ban would improve their working environment in other respects, such as making the unit safer (27\%), creating less work (12\%) or decreasing client aggression (9\%) (Table 2). While 66\% agreed that a total smoking ban would help staff stop smoking, fewer (38\%) agreed that it would do so for clients (Table 2). A majority agreed that a smoking ban would improve patients' physical health (65\%), and $41 \%$ agreed that it would increase patient quality of life in general (Table 2).

A majority (69\%) of respondents were either uncertain or did not agree that a total smoking ban would increase the quality of care overall, and $71 \%$ were either uncertain or did not agree that a total smoking ban would improve patient mental health (Table 2). In excess of $80 \%$ of respondents were either uncertain or disagreed that a total smoking ban would reduce medication use, increase rapport between patients or make patients happier (Table 2 ). There were no significant differences between the responses of clinical and non-clinical staff regarding the perceived benefits of a total smoking ban.

\section{Clinician perceived barriers to a total smoking ban}

Details of clinicians' perceived barriers to a successful total smoking ban are provided in Table 3. Nearly all clinicians indicated a fear of patient aggression (89\%), and most agreed that patients would continue to smoke (72\%). More than half of the respondents indicated a lack of staff capacity to enforce the ban as a barrier to a successful total smoking ban, with such capacity being seen to be limited by staff resistance to change, and a lack of knowledge, confidence and skills among staff. In addition, a lack of organisational support in the form of information, training, processes, resources and systems was expressed by between $35 \%$ and $49 \%$ of clinicians (Table 3). 


\begin{tabular}{|c|c|c|c|c|c|c|}
\hline & \multicolumn{2}{|c|}{ Clinical Staff } & \multicolumn{2}{|c|}{ Non-Clinical Staff } & \multicolumn{2}{|c|}{ All Staff } \\
\hline & $\%$ & $(n)$ & $\%$ & $(n)$ & $\%$ & (n) \\
\hline \multicolumn{7}{|c|}{ Do you support the statement that smoking should be totally banned throughout the Area's mental health services?a } \\
\hline Strongly Unsupportive & 10 & 7 & 6 & 6 & 7 & 13 \\
\hline Unsupportive & 16 & 12 & 13 & 14 & 14 & 26 \\
\hline No view either way & 10 & 7 & 13 & 14 & 12 & 21 \\
\hline Supportive & 30 & 22 & 34 & 37 & 33 & 59 \\
\hline Strongly supportive & 34 & 25 & 34 & 37 & 34 & 62 \\
\hline \multicolumn{7}{|c|}{ Do you agree with the statement that smoking should be totally banned on the unitb } \\
\hline Strongly disagree & 7 & 5 & & & & \\
\hline Disagree & 19 & 14 & & & & \\
\hline Unsure & 19 & 14 & & & & \\
\hline Agree & 22 & 16 & & & & \\
\hline Strongly agree & 32 & 23 & & & & \\
\hline
\end{tabular}

a Clinical $n=73$; Non-clinical $n=108 ;$ All $n=181$

bClinical $n=72$

\section{Support for a total smoking ban}

Levels of clinical and non-clinical staff support for total smoking bans within the mental health service generally, and the level of clinical staff support for such a ban in their specific unit are provided in Table 4. Approximately two thirds of both clinical (64\%) and non-clinical respondents (68\%) supported a total ban within mental health services generally, and $54 \%$ of clinicians supported the implementation of such a ban in their own unit (Table 4). The difference in the proportion of clinicians supporting a ban in mental health services generally, and the proportion supporting a ban in their own unit was statistically significant $(\mathrm{p}>0.001)$.

Chi square analysis indicated no statistically significant differences in support for smoking bans in mental health services generally between clinical and non-clinical staff respondents.

\section{Association between clinician perceived benefits and barriers to a total smoking ban and their level of support for such a ban}

Of the 9 demographic characteristics, and the 33 statements regarding clinician perceived benefits and barriers to a successful total smoking ban, 11 were found to be significant at $\mathrm{p}<.01$ (Table 5).

Logistic regression analysis results (Table 6) indicated that one variable was significantly associated with clinical staff support for a smoking ban in their own unit at p < .01. Respondents who believed a smoking ban would help patients to stop smoking were approximately 23 times more likely to support a smoking ban in their own unit than those who did not hold this view $(\mathrm{p}=.001)$.

\section{Discussion}

This study has identified clear and consistent support for a total smoking ban in inpatient mental health services from a majority of both clinical and non-clinical staff, with little difference between these groups. Despite this support, and acknowledgement of the benefits for both staff and patients of such a ban, significant barriers to the success of a ban were expressed by staff, particularly with regard to fear of patient aggression and concerns regarding clinician capacity and organisational support for the ban. The only perceived benefit or barrier that was significantly associated with clinician support for a ban was the view that a ban would assist patients to quit smoking. These findings suggest that the introduction of total smoking bans can be supported by staff, but that maximizing such support is contingent on the implementation of strategies that address staff lack of knowledge of evidence regarding both the benefits of a smoking ban and the lack of a negative impact on patient behaviour, and of strategies that address staff capacity and provide organizational support for clinicians.

Although methodological differences between studies limit the ability to compare findings, the level of staff support observed in this study appears greater than that previously reported $[14,20,29]$, and similar to that reported in the UK [30]. Temporal and jurisdictional differences may have contributed to the higher level of support observed in this study. In particular, the differences in outcomes may be attributed in part to this study being conducted in the context of a state-wide implementation of a smoke free policy in all health services, and of local 
strategies associated with its imminent implementation. To the extent that such a context contributed to the observed higher level of support, the findings confirm the previously reported importance of a systems approach to the successful implementation of a smoking ban specifically $[21,38]$, and to organisational and clinical practice change generally [39].

The findings of a high prevalence of agreement by staff regarding the benefits of a total smoking ban on improving the workplace environment and working conditions are consistent with previous findings [20]. The results are also consistent with the findings that such improvements can be obtained following the implementation of total smoking bans in psychiatric facilities [40]. In contrast, the low levels of respondent agreement regarding possible benefits in terms of increased safety and decreased client aggression is not supported by evidence, as such benefits are able to be realized when a total smoking ban is implemented $[10,19]$. These latter findings suggest that a more effective communication of the broader range of benefits that can accrue from the implementation of a total smoking ban is needed. Education addressing the benefits of total smoking bans have been described as a key component in the sustainability of total smoking bans [24].

A similar pattern of findings was evident with regard to perceived benefits of a total smoking ban for patients. The finding that a majority of staff considered that the implementation of a ban would be beneficial for patient physical health is consistent with evidence suggesting such a benefit is possible $[19,25]$. However, the findings that a minority of staff considered that the implementation of such a ban would improve patient quality of life, mental health or help patients to stop smoking suggest that the potential benefits for patients are viewed quite narrowly. Research is required to determine whether these improvements for patients do occur.

Almost three quarters of staff agreed that patients would continue to smoke under a total smoking ban, a finding that is consistent with the findings of previous research that staff believe that patients will resist smoking bans $[19,26]$. Studies of patient views however indicate a degree of acceptance of smoking bans [19,25]. Studies of the effectiveness of total smoking bans on patient smoking behaviour have indicated that, although some patients continue to smoke after their implementation $[10,29]$, smoking is less than prior to the implementation of a ban [14]. In a survey of forensic psychiatric inpatients' views, participants who smoked cited seeing staff and other patients smoking as barriers to quitting [41]. The advent of a total smoke-free environment offers an opportunity for changing tobacco use. This in itself is a step closer towards being a non-smoker, an opportunity that is unavailable in units where smoking is permitted $[42,43]$. In addition, without continuity of care and cessa- tion support after discharge, smoking bans in inpatient settings risk having no long-term effect on patient quit attempts [44].

Almost all clinical staff (89\%) expressed a fear of patient aggression. Evidence suggests that although this is a common concern among mental health staff [26-28], no significant increase in patient aggression occurs following the implementation of a total smoking ban [10,45-47]. More commonly, evidence suggests that following the implementation of such a ban an increase in patient [19] and staff support is evident [10,14,48-50], and levels of patient aggression are either unchanged or reduced $[10,14]$. This view may be related to a lack of skills or confidence in providing nicotine dependence treatment $[24,26]$.

There was a low level of agreement that a total smoking ban would increase the quality of care overall. There was also little support for the view that a total smoking ban would improve patient mental health. These results may suggest a view that treating smoking is not valued as a clinical role, nor that it would benefit the health of patients. These findings suggests that considerable system change and staff support is required to provide an environment where a primary prevention approach such as nicotine dependence treatment can be sustained $[22,24,51]$.

More than half of the respondents indicated a lack of knowledge, confidence and skills to provide care in the context of a total smoking ban, and between a third and half of respondents perceived a lack of organisational support in the form of the provision of information, training, organisational processes, systems and resources. This is a consistent finding in research regarding staff attitudes towards the implementation of smoking bans $[10,20-22,24]$, and the provision of nicotine dependence treatment to mental health patients $[42,44]$. Such a consistency of findings suggests a clear need for health care services to implement smoking bans in a manner that includes strategies that address leadership, systems development, and staff training [21,22,24,42,44,51]. The finding that staff involved in this study expressed such views in the context of a system-wide approach to the implementation of a total smoking ban may indicate that the planned implementation strategies may not have been adequate, or that the impact of such strategies had yet to be experienced by staff. A follow up study of staff attitudes following the implementation of the smoking ban is required to determine the success of the implementation strategy in addressing these issues.

Only one perceived benefit or barrier was significantly associated with clinician support for a ban in their own unit - the belief that a ban would help patients to stop smoking. Such a finding suggests that clinicians are more likely to support a ban if they believe it will have a clini- 
Table 5: Association between clinician perceived benefits and barriers to a successful ban, and their support for such a ban in their unit

\begin{tabular}{|c|c|c|c|c|}
\hline & $\begin{array}{c}\text { clinicians that support } \\
\text { a total ban }\end{array}$ & $\begin{array}{l}\text { clinicians that do not } \\
\text { support a ban }\end{array}$ & $x^{2}$ & $\mathrm{p}$ \\
\hline Smoker & $4 \%$ & $15 \%$ & 7.503 & .006 \\
\hline $\begin{array}{l}\text { Agreement with perceived positive } \\
\text { impacts }\end{array}$ & & $\%$ agreement & & \\
\hline Improve patient physical health & 45 & 24 & 8.829 & .003 \\
\hline Improve working conditions & 44 & 17 & 15.700 & .000 \\
\hline Help staff stop smoking & 44 & 22 & 9.063 & .003 \\
\hline Help patients stop smoking & 38 & 3 & 29.653 & .000 \\
\hline Makes the unit safer & 21 & 4 & 8.224 & .004 \\
\hline Increase patient quality of life & 32 & 8 & 12.365 & .000 \\
\hline Improve patient mental health & 29 & 6 & 13.730 & .000 \\
\hline Increase the quality of care & 25 & 4 & 11.885 & .001 \\
\hline \multicolumn{5}{|c|}{ Agreement with clinical issues of concern } \\
\hline Smoking bans aren't sustainable & 10 & 22 & 7.667 & .006 \\
\hline Lack of staff knowledge & 37 & 16 & 8.713 & .003 \\
\hline
\end{tabular}

cally beneficial outcome. Perhaps a potential strategy for encouraging staff support for a smoking ban in mental health inpatient settings is to emphasise the clinical and physical well-being benefits of a smoking ban, not just its environmental impacts, or the need for compliance with an organisational policy. The finding in this study of $69 \%$ of clinicians believing that a ban will improve a patient's physical health lends further support for such a proposal. Providing education and training to strengthen this believe may motivate staff to support the smoking ban $[22,24,26]$, and skill staff to help patients cope with their concerns about tolerating a period of abstinence or a quit attempt.

The findings of the present study need to be considered in the context of a number of its methodological characteristics. First, although comparable to previous studies $[20,29,30]$ the response rates, particularly for clinical staff, suggest that the results may not be representative of all staff. The extent to which the observed results reflect either an under or overestimate of the views of all staff is not known. Second, as the study was conducted in a single health service, the findings may not be generalisable to mental health services either elsewhere in the state or more broadly. However, a number of the findings appear consistent with the results of a previous study of the views of nurse unit managers across the state. For example, $69 \%$ of nurse unit managers state-wide [26] and $72 \%$ of clinicians in the current study report that patients aren't interested in quitting and will continue to smoke.
Although this was a study of staff views, further research is required to ascertain patient views towards total smoking bans. International research indicates that staff view a total smoking ban as more disruptive than patients [14]. For example, more staff than patients thought tobacco smoke was a source of conflict with staff or patients under a total smoking ban, and staff viewed co-habitation between smokers and non-smokers as more difficult under a total smoking ban [14]. Importantly, patients have reported to be more optimistic about being able to quit after an inpatient stay in a facility with a total smoking ban [25].

\section{Conclusions}

Although it is acknowledged that implementing a total smoking ban in a setting that has an historical culture of acceptance of tobacco smoking will require significant attitudinal and system changes $[21,24,26]$, strong leadership and staff training and support [24], there is a growing body of evidence to indicate that total smoking bans can be successfully implemented in psychiatric hospitals $[10,18,24]$. There is a clear need to more effectively communicate to staff the evidence that consistently applied smoking bans do not increase patient aggression, the benefits of smoking bans in aiding the delivery of smoking cessation care, and the benefits of both smoking bans and such care in aiding patients to stop smoking. The successful implementation of such bans in this setting is of particular importance as mental health treatment set- 
Table 6: Results of the logistic regression analysis of the association between clinician perceived benefits and barriers to a total smoking ban and their support for such a ban in their unit

\begin{tabular}{|c|c|c|c|c|c|c|c|}
\hline \multirow{2}{*}{$\begin{array}{l}\text { A total smoking ban in own } \\
\text { unit }\end{array}$} & \multirow[t]{2}{*}{ B } & \multirow[t]{2}{*}{ SE } & \multirow[t]{2}{*}{$\mathrm{df}$} & \multirow[t]{2}{*}{$\mathrm{p}$} & \multirow[t]{2}{*}{ Odds } & \multicolumn{2}{|c|}{ Confidence Intervals } \\
\hline & & & & & & Lower & Upper \\
\hline $\begin{array}{l}\text { Will help patients stop } \\
\text { smoking }\end{array}$ & 3.140 & .921 & 1 & .001 & 23.107 & 3.801 & 140.473 \\
\hline $\begin{array}{l}\text { Concerned that staff lack } \\
\text { knowledge }\end{array}$ & 1.738 & .738 & 1 & .018 & 5.688 & 1.340 & 24.154 \\
\hline Non-smoker & 2.756 & 1.167 & 1 & .018 & 15.739 & 1.598 & 154.987 \\
\hline
\end{tabular}

tings remain the only sector of health care that have failed to implement total smoking bans and systematically offer nicotine dependence treatment to patients. Such a failing perpetuates the health inequalities experienced by those with mental illness who smoke.

\section{Competing interests}

The authors declare that they have no competing interests.

\section{Authors' contributions}

All authors participated in the design of the study, development of the survey tool, and read and approved the final manuscript. PW completed data entry, data analysis, and drafting of the manuscript. PW, JB and JW were involved in critical revision of the manuscript.

\section{Acknowledgements}

This research was supported by the Commonwealth Department of Health and Ageing, Australia. The authors would like to thank the survey respondents for their participation.

\section{Author Details}

1School of Psychology, University of Newcastle, University Drive, Newcastle, 2308 Australia, 2 Hunter New England Population Health, Hunter New England Area Health Service, Longworth Avenue, Wallsend, 2287 Australia, ${ }^{3}$ School of Medicine and Public Health, University of Newcastle, University Drive, Newcastle, 2308 Australia, ${ }^{4}$ Centre for Brain and Mental Health Research, Faculty of Health, University of Newcastle, University Drive, Newcastle, 2308 Australia, ${ }^{5}$ School of Psychiatry, University of New South Wales at St Vincent's Hospital, 390 Victoria Street, Darlinghurst, 2010 Australia, ${ }^{6}$ Schizophrenia Research Institute, 405 Liverpool Street, Darlinghurst, 2010 Australia and ${ }^{7}$ Mental Health Services, Hunter New England Area Health Service, The Mater Hospital, Edith Street, Waratah, 2298 Australia

Received: 17 December 2009 Accepted: 25 June 2010 Published: 25 June 2010

\section{References}

1. Begg S, Vos T, Barker B, Stevenson C, Stanley L, Lopez AD: The burden of disease and injury in Australia, 2003. In AIHW Cat No PHE 82 Australian Institute of Health and Welfare; 2007

2. Mokdad AH, Marks JS, Stroup DF, Gerberding JL: Actual causes of death in the United States, 2000. Journal of the American Medical Association 2004, 291:1238-1245.

3. Jablensky A, McGrath J, Herrman H, Castle D, Gureje O, Morgan V, Korten A: National survey of mental health and wellbeing. Bulletin 1. People living with a psychotic illness: an Australian study 1997-98. Canberra: Commonwealth of Australia; 1999.

4. Davidson S, Judd F, Jolley D, Hocking B, Thompson S, Hyland B: Cardiovascular risk factors for people with mental illness. Australian and New Zealand Journal of Psychiatry 2001, 35:196-202.
5. Australian Institute of Health and Welfare: 2007 National Drug Strategy Household Survey: detailed findings. Canberra: AlHW; 2008. Drug statistics series no 22. Cat. no. PHE 107

6. Fowler IL, Carr VJ, Carter NT, Lewin TJ: Patterns of current and lifetime substance use in schizophrenia. Schizophrenia Bulletin 1998, 24:443-455.

7. Reichler H, Baker A, Lewin T, Carr V: Smoking among in-patients with drug-related problems in an Australian psychiatric hospital. Drug and Alcohol Review 2001, 20:231-237.

8. Lineberry TW, Allen JD, Nash J, Galardy CW: Population-based prevalence of smoking in psychiatric inpatients: a focus on acute suicide risk and major diagnostic groups. Comprehensive Psychiatry 2009, 50:526-532.

9. Coghlan R, Lawrence D, Holman CDJ, Jablensky AV: Duty to Care: Physical illness in people with mental illness: Consumer Summary. In Department of Public Health and Department of Psychiatry and Behavioural Science Perth: University of Western Australia; 2001.

10. Lawn S, Pols R: Smoking bans in psychiatric inpatient settings? A review of the research. Australian and New Zealand Journal of Psychiatry 2005, 39:866-885

11. World Health Organization: WHO evidence based recommendations on the treatment of tobacco dependence. World Health Organization European Partnership Project to Reduce Tobacco Dependence, Copenhagen; 2001.

12. Fichtenberg CM, Glantz SA: Effect of smoke-free workplaces on smoking behaviour: Systematic review. BMJ 2002, 325:188-195

13. Chapman S, Borland R, Scollo M, Brownson RC, Dominello A, Woodward S: The impact of smoke-free workplaces on declining cigarette consumption in Australia and the United States. American Journal of Public Health 1999, 89:1018-1023.

14. Etter M, Khan AN, Etter J-F: Acceptability and impact of a partial smoking ban followed by a total smoking ban in a psychiatric hospital. Preventive Medicine 2008, 46:572-578.

15. Wakefield M, Roberts $L$, Owen N: Trends in prevalence and acceptance of workplace smoking bans among indoor workers in South Australia. Tobacco Control 1996, 5:205-208.

16. Freund M, Campbell E, Paul C, Sakrouge R, Wiggers J: Smoking care provision in smoke-free hospitals in Australia. Preventive Medicine 2005, 41:151-158.

17. McNeill A: Smoking and patients with mental health problems. NHS Health Development Agency; 2001.

18. Williams JM: Eliminating tobacco use in mental health facilities: patients' rights, public health, and policy issues. JAMA 2008 , 299:571-573.

19. el-Guebaly N, Cathcart J, Currie S, Brown D, Gloster S: Public health and therapeutic aspects of smoking bans in mental health and addiction settings. Psychiatric Services 2002, 53:1617-1622.

20. Willemsen MC, Goörts CA, Van Soelen P, Jonkers R, Hilberink SR: Exposure to environmental tobacco smoke (ETS) and determinants of support for complete smoking bans in psychiatric settings. Tobacco Control 2004, 13:180-185

21. Campion J, Lawn S, Brownlie A, Hunter E, Gynther B, Pols RG: Implementing smoke-free policies in mental health units: Learning from unsuccessful experience. Aust Psychiatry 2008, 16:92-97. 
22. Wye P, Bowman J, Wiggers J, Baker A, Knight J, Carr V, Terry M, Clancy R: Smoking care policies and procedures in Australian psychiatric facilities. Psychiatr Serv 2009, 60:100-107.

23. Reilly P, Murphy L, Alderton D: Challenging the smoking culture within a mental health service supportively. International Journal of Mental Health Nursing 2006, 15:272-278.

24. Lawn S, Campion J: Factors associated with success of smoke-free initiatives in Australian psychiatric inpatient units. Psychiatric Services 2010, 61:300-305.

25. Shmueli D, Fletcher L, Hall S, Hall S, Prochaska J: Changes in psychiatric patients' thoughts about quitting smoking during a smoke-free hospitalization. Nicotine \& Tobacco Research 2008, 10:875-81.

26. Wye P, Bowman J, Baker A, Wiggers J, Carr V, Terry M, Knight J, Clancy R: Providing Smoking Care to Psychiatric Inpatients: the Views of Australian Nurse Managers. Journal of Psychiatric \& Mental Health Nursing 2010, 17:319-327

27. Stubbs J, Haw C, Garner L: Survey of staff attitudes to smoking in a large psychiatric hospital. Psychiatric Bulletin 2004, 28:204-207.

28. Dickens GL, Stubbs JH, Haw CM: Smoking and mental health nurses: a survey of clinical staff in a psychiatric hospital. Journal of Psychiatric and Mental Health Nursing 2004, 11:445-451.

29. Bloor RN, Meeson L, Crome IB: The effects of a non-smoking policy on nursing staff smoking behaviour and attitudes in a psychiatric hospital. Journal of Psychiatric and Mental Health Nursing 2006, 13:188-196.

30. McNally L, Oyefeso A, Annan J, Perryman K, Bloor R, Freeman S, Wain B, Andrews H, Grimmer M, Crisp A, Oyebode D, Ghodse AH: A survey of staff attitudes to smoking-related policy and intervention in psychiatric and general health care settings. Journal of Public Health 2006, 28:192-196.

31. Etter M, Etter JF: Acceptability and impact of a partial smoking ban in a psychiatric hospital Prev. Med. 2007, 44:64-69.

32. Thorton B, Knox D: "Not in my back yard': The situational and personality determinants of oppositional behaviour. Journal of Applied Social Psychology 2006, 32:2554-2574.

33. Anderson PA, Buller DB, Voeks JH, Borland R, Helme D, Bettinghaus EP. Predictors of support for environmental tobacco smoke bans in state government. American Journal of Preventive Medicine 2006, 33:340-351.

34. Walsh RA, Bowman BA, Tzelepis F, Lecathelinais C: Smoking cessation interventions in Australian drug treatment agencies: a national survey of attitudes and practices. Drug and Alcohol Review 2005, 24:235-244.

35. SPSS. SPSS. SPSS, Inc: Chicago, IL; 2006.

36. Howell DC: Statistical methods for psychology. In Thomson Learning Pacific Grove, California; 2002.

37. Handbook of Psychology. In Vol 2 Research methods in psychology Edited by: Schinka JA, Velicer WR. John Wiley \& Sons Inc Hoboken, NJ; 2003.

38. Freund MAG, Campbell EM, Paul CL, Wiggers JH, Knight JJ, Mitchell EN: Provision of smoking care in NSW hospitals: Opportunities for further enhancement. NSW Public Health Bull 2008, 19:50-55.

39. Wensing $M, G$ rol R: Determinants of effective change. Improving patient care: the implementation of change in clinical practice. In Improving Patient Care: The Implementation of Change in Clinical Practice Edited by: Grol R, Wensing M, Eccles M. Edinburgh: Elsevier Butterworth Heinemann; 2005:94-108.

40. Parks J, Jewell P: Technical report on smoking policy and treatment in state operated psychiatric facilities. National Asociation of State Mental Health Program Directors, Medical Directors Council, Alexandria, VA; 2006.

41. Dickens G, Stubbs J, Popham R, Haw C: Smoking in a forensic psychiatric service: A survey of inpatients' views. Journal of Psychiatric and Mental Health Nursing 2005, 12:672-678.

42. Wye P, Bowman J, Wiggers J, Baker A, Carr V, Terry M, Knight J, Clancy R: An audit of the prevalence of nicotine dependence treatment in an Australian psychiatric hospital. Australian \& New Zealand Journal of Public Health 2010, 34:298-303.

43. Goldberg J: Successful change i tobacco use in schizophrenia. Journal of the American Psychiatric Nurses Association 2010, 16:30-35

44. Prochaska JJ, Fletcher L, Hall SE, Hall SM: Return to smoking following a smoke-free psychiatric hospitalization. American Journal of Addiction 2006, 15:15-22.

45. Haller E, McNiel DE, Binder RL: Impact of a smoking ban on a locked psychiatric unit. Journal of Clinical Psychiatry 1996, 57:329-332.

46. Villari V, Barzega G: Smoking bans on psychiatric units: Boundaries and health promotion. Psychiatric Services 2008, 59:1063-1064.
47. Velasco J, Eells TD, Anderson R, Head M, Ryabik B, Mount R, Lippmann S: A two-year follow-up on the effects of a smoking ban in an inpatient psychiatric service. Psychiatr Serv 1996, 47:869-871.

48. Resnick M, Bosworth E: A smoke-free psychiatric unit. Hospital and Community Psychiatry 1989, 40:525-527.

49. Taylor NE, Rosenthal RN, Chabus B, Levine S, Hoffman AS, Reynolds J, Santos L, Willets I, Friedman P: The feasibility of smoking bans on psychiatric units. General Hospital Psychiatry 1993, 15:36-40.

50. Patten CA, Bruce BK, Hurt RD, Offord KP, Richardson JW, Clemensen LR, Persons SM: Effects of a smoke-free policy on an inpatient psychiatric unit. Tobacco Control 1995, 4:372-379.

51. Ziedonis DM, Williams JM, Smelson D: Serious mental illness and tobacco addiction: A model program to address this common bu neglected issue. The American Journal of the Medical Sciences 2003, 326:223-230.

\section{Pre-publication history}

The pre-publication history for this paper can be accessed here: http://www.biomedcentral.com/1471-2458/10/372/prepub

\section{doi: 10.1186/1471-2458-10-372}

Cite this article as: Wye et al., Total smoking bans in psychiatric inpatient services: a survey of perceived benefits, barriers and support among staff BMC Public Health 2010, 10:372

\section{Submit your next manuscript to BioMed Central and take full advantage of:}

- Convenient online submission

- Thorough peer review

- No space constraints or color figure charges

- Immediate publication on acceptance

- Inclusion in PubMed, CAS, Scopus and Google Scholar

- Research which is freely available for redistribution

Submit your manuscript at www.biomedcentral.com/submit
C) Biomed Central 